\title{
Neonatal pain and heart rate variability in preterm infants treated with surfactant: a pilot study
}

\author{
Nilufer Okur, M.D. ${ }^{a}$, Nurdan Uras, Assoc. Prof., Mehmet Buyuktiryaki, M.D. ${ }^{a}$, Mehmet Y. Oncel, M.D. ${ }^{b}$, \\ Fatma N. Sari, Assoc. Prof. ${ }^{a}$, Erbu Yarci ${ }^{a}$, Evrim A. Dizdar, Assoc. Prof. ${ }^{a}$, Fuat E. Canpolat, Assoc. Prof. ${ }^{a}$ \\ and Serife S. Oguz, Assoc. Prof.
}

\begin{abstract}
Objective. We aimed to assess the pain perception of preterm infants treated with different surfactant administration techniques by using heart rate variability (HRV).

Methods. Preterm infants who required surfactant therapy for RDS were randomized to INSURE or MIST groups. HRV analysis was performed by Newborn Infant Parasympathetic Evaluation monitor. HRV was recorded before, during and after surfactant administration. Pain assessment was determined by Premature Infant Pain Profile (PIPP) score.

Results. Fourteen infants were enrolled in the study. Demographic characteristics of the groups were similar. PIPP scores did not differ between INSURE and MIST groups $(p=0.05)$. Statistically significant difference in median HRV during surfactant administration was observed between INSURE and MIST groups (52 vs. $56, \mathrm{p}=0.03$ ). HRV analysis was similar between groups before and after surfactant administration.

Conclusion. Surfactant administration with MIST technique might be more comfortable for preterm infants with RDS. However further studies with larger series are needed.

Key words: Intubation, premature infant, pain, pulmonary surfactant.
\end{abstract}

http: / / dx.doi.org/10.5546/ aap.2019.eng.397

To cite: Okur N, Uras N, Buyuktiryaki M, Oncel MY, et al. Neonatal pain and heart rate variability in preterm infants treated with surfactant: a pilot study. Arch Argent Pediatr 2019;117(6):397-401.

a. Division of Neonatology. Zekai Tahir Burak Maternity Teaching Hospital, Ankara, Turkey.

b. Katip Celebi University Faculty of Medicine, Neonatal Intensive Unit, Izmir, Turkey.

E-mail address:

Nilufer Okur, M.D.: n.matur@hotmail.com

Funding:

None.

Conflict of interest:

None.

Received: 7-9-2018

Accepted: 6-27-2019

\section{INTRODUCTION}

Surfactant therapy is applied through two different techniques in order to treat respiratory distress syndrome (RDS). The INSURE (intubate, surfactant, extubate) method is the most common way for surfactant treatment. ${ }^{1}$ Recently, a new method, minimally invasive surfactant therapy (MIST), has been developed to administer surfactant. Surfactant administration via a thin endotracheal catheter during spontaneous breathing with continuous positive airway pressure (CPAP) has come into clinical use with this method. ${ }^{2-5}$ However, not enough data and experience exist on how MIST and INSURE techniques affect pain perception in newborns.

It is difficult to evaluate pain perception in infants. Presently, pain and/or discomfort assessment is mainly based on behavioral pain scales. However, these scoring systems are based on items like facial movements, body movements, or comfort ability and therefore subjected to significant inter- and intra-observer variability.$^{6-9}$

Recent studies indicated that sympathetic and parasympathetic influences in response to painful or stressful stimulus can be measured by variations of RR heart rate intervals. It has been shown that the Newborn Infant Parasympathetic Evaluation (NIPE) index could assess the parasympathetic tone and evaluate prolonged pain, acute pain, discomfort, and comfortable stimulations. In this study, we aimed to compare the pain perceptions of preterm infants treated with different surfactant administration techniques using heart rate variability (HRV) as measured by the NIPE index and PIPP score.

\section{METHODS}

This prospective randomized controlled study was conducted in the neonatal intensive care unit (NICU) of Zekai Tahir Burak Maternity Teaching Hospital between May and June 2015. Preterm infants with 26-32 weeks of gestational age and $\leq 1250 \mathrm{~g}$ birthweight who suffered from RDS were enrolled. This trial was approved by the Zekai 
Tahir Burak Maternity and Teaching Hospital Ethics Committee, and written parental consent was obtained from the parents of each infant.

Preterm infants requiring surfactant therapy for RDS were randomly assigned to either INSURE or MIST groups when they were admitted to the NICU. NIPE monitor (Mdoloris Medical Systems, France) was attached to each infant before surfactant administration. Infants with major congenital anomalies; PPV or intubation in the delivery room; structural cardiac anomalies; exposure to painful procedures like venipuncture, suctioning, blood sampling, or heel prick 30 minutes before assessment; and lack of parental consent were excluded. RDS was diagnosed in infants exhibiting the following symptoms: need for supplemental oxygen, tachypnea, grunting, and intercostal retractions; it was confirmed by typical $x$-ray and blood gas findings. A suggested protocol would be to treat infants $\leq 26$ weeks' gestation when $\mathrm{FiO}_{2}$ requirements $>0.30$ and infants $>26$ weeks' when $\mathrm{FiO}_{2}$ requirements $>0.40$.

\section{Treatment strategies}

Surfactant therapy via the MIST procedure was applied to the infants using a $5 \mathrm{~F}$, flexible, sterile nasogastric tube. Surfactant was administered in 1 bolus in 30 to 60 seconds and the tracheal catheter was immediately withdrawn.

Infants who received surfactant via the INSURE technique were first orally intubated with a double-lumen endotracheal tube, and surfactant was instilled to the trachea in 30 seconds. Manual lung inflation by a T-piece device at $20 / 5 \mathrm{cmH}_{2} \mathrm{O}$ pressure was performed during the surfactant instillation, and then the infant was promptly extubated.

Poractant alfa (Curosurf; Chiesi Farmaceutici, Parma, Italy) was administered to all infants (200 mg/ kg/dose for each patients) in the study. NIPE index of each infant was recorded consecutively, before, during, and after surfactant administration. The Premature Infant Pain Profile (PIPP) was used to measure behavioral and physiological responses of infants to pain. ${ }^{10}$

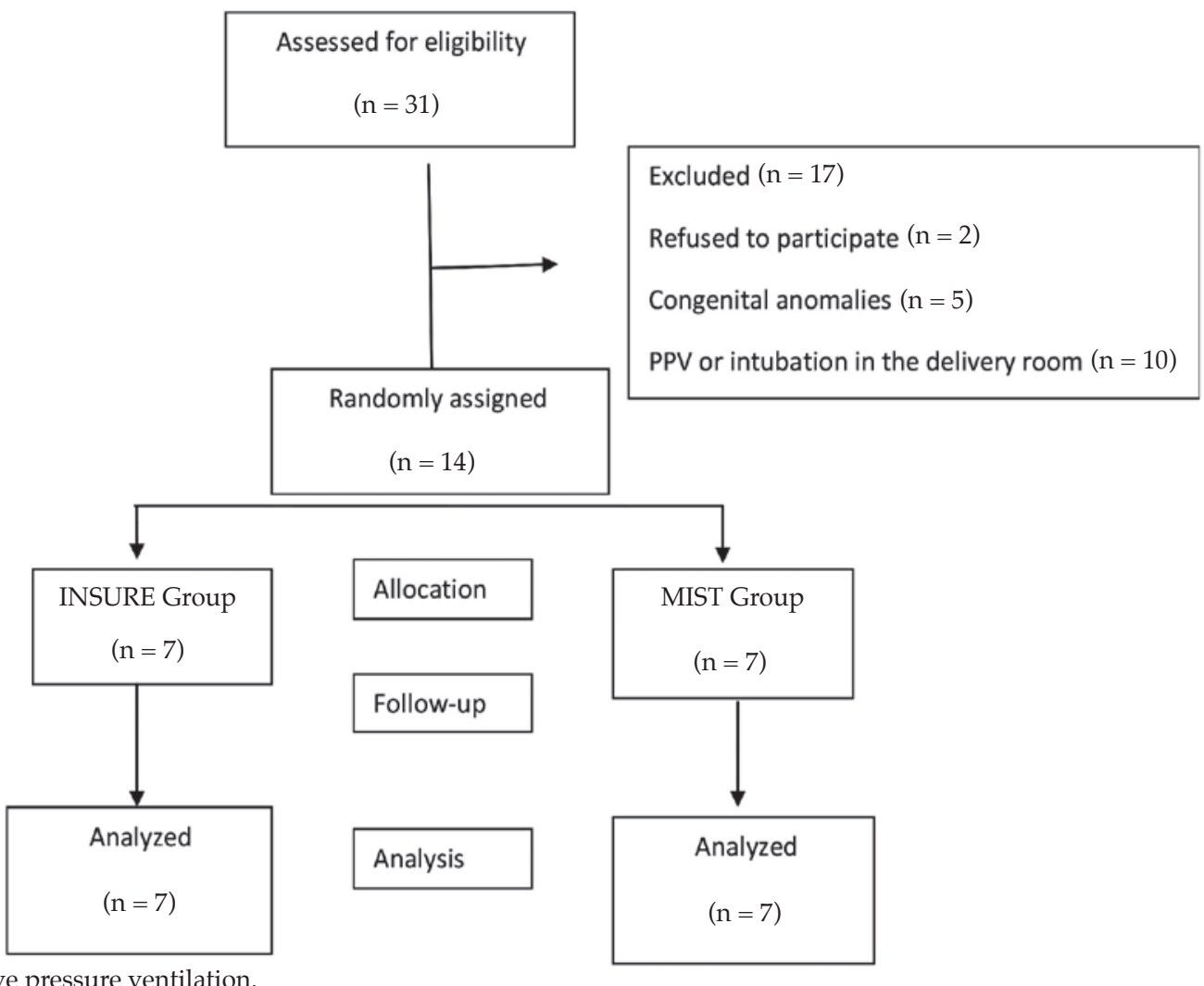

PPV: positive pressure ventilation. 


\section{Statistical analysis}

Statistical analyses were performed using the statistical package SPSS for Windows v. 17.0 (SPSS Inc., Chicago, Illinois). Normally distributed data were given as mean and $\mathrm{SD}$; others presented as median and range. Demographic percentage and mean outcome measures of patients were compared between the two groups with Fisher's exact test, a chisquared test, and a $t$-test. A $p$ value of $<0.05$ was considered statistically significant.

The sample size was calculated using data derived from our NICU records from the prestudy period. Infants treated with surfactant had a NIPE index of 56 (geometric mean, log-normally distributed) with a standard deviation of 9 during the pre-study period. To show a $30 \%$ reduction in NIPE index with a two-sided $\alpha$-error of 0.05 and the $\beta$-error of $0.2,14$ infants were required for randomization.

\section{RESULTS}

Fourteen infants were enrolled in the study: INSURE: $\mathrm{n}=7$; MIST: $\mathrm{n}=7$ (Figure 1). Mean \pm SD) gestational age of the infants was $29.1 \pm 1.5$ in the INSURE group and $29.4 \pm 1.2$ in the MIST group ( $p>0.05)$. Mean $( \pm S D)$ birthweights of the infants were $1107 \pm 103 \mathrm{~g}$ in the INSURE group and $1127 \pm 85 \mathrm{~g}$ in the MIST group ( $\mathrm{p}>0.05)$. Demographic characteristics of the groups were shown in Table 1.

TABLE 1. Demographic characteristics of the groups

\begin{tabular}{lccc}
\hline & $\begin{array}{c}\text { INSURE } \\
(\mathbf{n}=7)\end{array}$ & $\begin{array}{c}\text { MIST } \\
(\mathbf{n}=7)\end{array}$ & $p$ \\
\hline Gestational age, week $^{\mathrm{a}}$ & $29.1 \pm 1.5$ & $29.4 \pm 1.2$ & 0.71 \\
Birth weight, ga $^{\text {a }}$ & $1107 \pm 103$ & $1127 \pm 85$ & 0.69 \\
Gender (Male), $\mathrm{n}_{\text {Caesarian delivery, } \mathrm{n}}$ & 4 & 3 & 0.50 \\
Antenatal steroid use, $\mathrm{n}$ & 5 & 6 & 0.50 \\
& 7 & 5 & 0.23 \\
\hline
\end{tabular}

${ }^{a}$ mean \pm standart deviation.
The PIPP scores and HRV variables of the groups are presented in Table 2 . The median PIPP scores were 10 (10-13) and 10 (8-12) in the INSURE and MIST groups, respectively. PIPP scores did not differ between infants in the INSURE and MIST groups $(p=0.053)$. A statistically significant difference in the median HRV of infants during surfactant administration was observed between the INSURE and MIST groups ( 52 vs. $56, p=0.03$ ). HRV analyses before and after surfactant administration were similar in both groups (Table 2). HRV index and PIPP score of each infant are shown in Table 3 . There was a significant correlation between NIPE values and PIPP scores during surfactant administration $\left(\mathrm{r}^{2}=-0,811, \mathrm{p}<0.0001\right)$.

\section{DISCUSSION}

In our study, we observed that the NIPE index was significantly higher during the surfactant administration in infants treated with MIST technique and also correlated with PIPP scores.

There is consensus that the endotracheal intubation procedure should be performed while the infant is adequately sedated. ${ }^{10,11}$ However, there is ongoing debate about whether or not sedation should be used during MIST, as the presence of spontaneous breathing is a prerequisite for the procedure. In the studies evaluating MIST technique no sedation was used. ${ }^{12}$ In our study we found that the MIST technique group had less pain compared to INSURE group. So, we suggested that surfactant administration with the MIST technique, thus, may be more comfortable for preterm infants with RDS.

Alexandre et al. compared HRV before and after standardized cocooning phases associated with the human voice and carried out: 1) by the mother and 2) by a third person. HRV was assessed and expressed as an index reflecting the parasympathetic tone. They showed that

TABLE 2. Comparison of HRV index and PIPP scores

\begin{tabular}{|c|c|c|c|}
\hline & $\begin{array}{l}\text { INSURE } \\
(\mathrm{n}=7)\end{array}$ & $\begin{array}{l}\text { MIST } \\
(n=7)\end{array}$ & $p$ \\
\hline HRV index, before of surfactant therapy & $64(53-68)$ & $62(58-80)$ & 0.805 \\
\hline HRV index, during of surfactant therapy & $52(50-55)$ & $56(50-75)$ & 0.038 \\
\hline HRV index, 20.min. after surfactant therapy & $56(54-60)$ & $61(52-80)$ & 0.053 \\
\hline HRV index, 40.min. after surfactant therapy & $60(50-69)$ & $61(54-82)$ & 0.456 \\
\hline HRV index, $60 . \mathrm{min}$. after surfactant therapy & $60(53-75)$ & $71(52-89)$ & 0.383 \\
\hline PIPP scores during surfactant therapy & $10(10-13)$ & $10(8-12)$ & 0.053 \\
\hline
\end{tabular}

Median (minimum-maximum). 
TABLE 3. NIPE index and PIPP score of each infant

\begin{tabular}{lccccccccc}
\hline Case & GW & BW & $\begin{array}{c}\text { Surfactant } \\
\text { technique }\end{array}$ & $\begin{array}{c}\text { NIPE index } \\
\text { Before of } \\
\text { surfactant } \\
\text { treatment }\end{array}$ & $\begin{array}{c}\text { NIPE index } \\
\text { During of } \\
\text { surfactant } \\
\text { treatment }\end{array}$ & $\begin{array}{c}\text { NIPE index } \\
\text { 20.min. after } \\
\text { surfactant } \\
\text { therapy }\end{array}$ & $\begin{array}{c}\text { NIPE index } \\
\text { 40.min. after } \\
\text { surfactant } \\
\text { therapy }\end{array}$ & $\begin{array}{c}\text { NIPE index } \\
\text { 60.min. after } \\
\text { surfactant } \\
\text { therapy }\end{array}$ & $\begin{array}{c}\text { PIPP } \\
\text { score }\end{array}$ \\
\hline 1 & 30 & 1150 & MIST & 62,00 & 56,00 & 61,00 & 57,00 & 52,00 & 10,00 \\
2 & 27 & 980 & MIST & 58,00 & 54,00 & 62,00 & 72,00 & 71,00 & 11,00 \\
3 & 29 & 1160 & MIST & 62,00 & 54,00 & 60,00 & 61,00 & 62,00 & 10,00 \\
4 & 31 & 1250 & MIST & 80,00 & 75,00 & 80,00 & 82,00 & 89,00 & 8,00 \\
5 & 30 & 1120 & MIST & 70,00 & 72,00 & 73,00 & 72,00 & 75,00 & 9,00 \\
6 & 30 & 1170 & MIST & 58,00 & 50,00 & 52,00 & 54,00 & 54,00 & 12,00 \\
7 & 29 & 1065 & MIST & 60,00 & 58,00 & 58,00 & 58,00 & 84,00 & 10,00 \\
8 & 29 & 1020 & INSURE & 53,00 & 50,00 & 56,00 & 50,00 & 53,00 & 12,00 \\
9 & 30 & 1200 & INSURE & 57,00 & 55,00 & 60,00 & 67,00 & 60,00 & 11,00 \\
10 & 28 & 1050 & INSURE & 60,00 & 53,00 & 56,00 & 58,00 & 55,00 & 12,00 \\
11 & 31 & 1220 & INSURE & 68,00 & 52,00 & 58,00 & 69,00 & 75,00 & 10,00 \\
12 & 31 & 1230 & INSURE & 64,00 & 52,00 & 56,00 & 60,00 & 64,00 & 11,00 \\
13 & 28 & 1030 & INSURE & 65,00 & 53,00 & 58,00 & 62,00 & 63,00 & 11,00 \\
14 & 27 & 1000 & INSURE & 66,00 & 51,00 & 54,00 & 54,00 & 55,00 & 13,00 \\
\hline
\end{tabular}

cocooning associated with the human voice enhances HRV in the preterm infant, indicating an increase in parasympathetic activity. ${ }^{13}$

Our study is strong in terms of revealing the stress levels of preterm infant treated with surfactant. Pain was assessed by both the PIPP scores and NIPE index, while different surfactant administration techniques were applied to the infants. PIPP score is a powerful scale that has been used in the objective assessment of pain in premature infants. Scarce information is available in the literature about the pain sensation that MIST practice can produce, and our trial presents results that will help illuminate this area of inquiry. In addition, current trial is the first study to compare PIPP score with NIPE index in preterm infants.

Our study has some limitations. First, HRV is controlled by the autonomic nervous system outflow, which can be altered by numerous factors, including maturation, environmental conditions, and/or drugs. Second it is a small sample sized study.

\section{CONCLUSION}

Our findings suggest that surfactant administration using the MIST technique might be more comfortable for preterm infants with RDS.

\section{REFERENCES}

1. Bohlin K, Gudmundsdottir T, Katz-Salamon M, Jonsson B, Blennow M. Implementation of surfactant treatment during continuous positive airway pressure. J Perinatol. 2007; 27(7):422-7.

2. Göpel W, Kribs A, Ziegler A, Laux R, et al. Avoidance of mechanical ventilation by surfactant treatment of spontaneously breathing preterm infants (AMV): an open-label, randomised, controlled trial. Lancet. 2011; 378(9803):1627-34.

3. Kribs A, Vierzig A, Hünseler C, Eifinger F, et al. Early surfactant in spontaneously breathing with nCPAP in ELBW infants-a single centre of our year experience. Acta Paediatr. 2008; 97(3):293-8

4. Kribs A, Härtel C, Kattner E, Vochem M, et al. Surfactant without intubation in preterm infants with respiratory distress: first multi-center data. Klin Padiatr. 2010;222(1):137.

5. Kribs A, Pillekamp F, Hünseler C, Vierzig A, Roth B. Early administration of surfactant in spontaneous breathing with nCPAP: feasibility and outcome in extremely premature infants (postmenstrual age $</=27$ weeks). Paediatr Anaesth. 2007; 17(4):364-9.

6. Grunau RE, Oberlander T, Holsti L, Whitfield MF. Bedside application of the Neonatal Facial Coding System in pain assessment of premature neonates. Pain. 1998; 76(3):27786.

7. Carbajal R, Paupe A, Hoenn E, Lenclen R, Olivier-Martin M. DAN: une échelle comportementale d'evaluation de la douleur aiguë du nouveauné. Arch Pediatr. 1997; 4(7):6238.

8. Stevens B, Johnston C, Petryshen P, Taddio A. Premature Infant Pain Profile: development and initial validation. Clin I Pain. 1996; 12(1):13-22.

9. Logier R, De Jonckheere J, Delecroix M, Keribedj A, et al. Heart rate variability analysis for arterial hypertension etiological diagnosis during surgical procedures under 
tourniquet. Conf Proc IEEE Eng Med Biol Soc. 2011; 2011:3776-9.

10. Friesen RH, Honda AT, Thieme RE. Changes in anterior fontanel pressure in preterm neonates during tracheal intubation. Anesth Analg. 1987; 66(9):874-8.

11. Pokela ML, Koivisto M. Physiological changes, plasma betaendorphin and cortisol responses to tracheal intubation in neonates. Acta Paediatr. 1994; 83(2):151-6.
12. Dargaville PA, Aiyappan A, De Paoli AG, Kuschel CA, et al. Minimally-invasive surfactant therapy in preterm infants on continuous positive airway pressure. Arch Dis Child Fetal Neonatal Ed. 2013; 98(2):F122-6.

13. Alexandre C, De Jonckheere J, Rakza T, Mur S, et al. Impact du cocooning et de la voix humaine sur le systéme nerveux autonome (SNA) del'enfant grand prématuré. Arch Pediatr. 2013; 20(9):963-8.

\title{
Child's respiratory and sleep health following mid-trimester amniocentesis
}

\author{
Danielius Serapinas, Prof. MD PhD ${ }^{a, b}$ and Daiva Bartkeviciene, Assoc Prof MD PhD. ${ }^{c}$
}

\begin{abstract}
Objective. The aim was to investigate the rates of respiratory and sleep disturbances in infants whose mothers experienced amniocentesis.

Material and methods. Infants whose mothers have undergone midterm amniocentesis (between 16 and 20 weeks) and no invasive procedure (controls) were enrolled.

Results. The study analyzed 50 infants whose mothers have undergone amniocentesis (amniocentesis group) and 47 controls. Amniocentesis group had higher incidence of sleep disturbances: 30 cases $(60 \%)$, compared with 11 controls $(23.4 \%)$ $(P=0.001)$. In the amniocentesis group there were 7 children (14\%) with asthma, while in the control group, asthma was confirmed in 1 child $(2.1 \%)(\mathrm{P}=0.032)$.

Conclusion. Our data triggers the hypothesis that associations between midterm amniocentesis, child's asthma and sleep disturbances may exist. These preliminary results reveal the importance of further studies and the need for the analysis of long term effects of invasive testing.

Key words: amniocentesis, informed consent, respiratory tract diseases, sleep disorders, infant.
\end{abstract}

http: / / dx.doi.org/10.5546/ aap.2019.eng.401

a. Department of Family Medicine, Medical Academy, Lithuanian University of Health Sciences, Kaunas, Lithuania.

b. Mykolas Romeris University, Vilnius, Lithuania.

c. Department of Obstetrics and Gynaecology, Faculty of Medicine, Vilnius University, Vilnius, Lithuania.

E-mail address:

Dr. Danielius Serapinas: dserapinas@gmail.com

Funding: None.

Conflict of interest: None.

Received: 9-9-2018

Accepted: 7-4-2019
To cite: Serapinas D and Bartkeviciene D. Child's respiratory and sleep health following mid-trimester amniocentesis. Arch Argent Pediatr 2019;117(6):401-404.

\section{INTRODUCTION}

The tendency of modern community to give birth at more advanced age conditioned that prenatal diagnostics methods became more frequently used in women's health care. Amniocentesis, a second trimester invasive test, is performed to detect chromosomal numeral and structural anomalies. ${ }^{1}$ However, despite their high sensitivity for detection rates, these procedures have their complication rates for the fetus and mother, including the fetal fluid embolism. ${ }^{2}$ The risks for fetus include not only miscarriage, with the excess risk of around 0.5-1\% above the background risk, ${ }^{3}$ but also there is a well-proved relationship between early amniocentesis and congenital anomaly (talipes). ${ }^{4}$ Despite these rare morphological consequences of amniocentesis, more frequent functional effects may occur that can have long-lasting consequences on a child's health and are not always observable at prenatal and perinatal stages. ${ }^{5}$ Functionally, the fetal lungs are extremely sensitive to the external mechanical effects. There are studies suggesting that respiratory disturbances such as neonatal pneumonia, meconium aspiration, atelectasis and tachypnea were more frequently found in the amniocentesis group. ${ }^{6-7}$ However, over the last 10 years, no studies were performed on the analysis of genetic amniocentesis and fetal respiratory health. Therefore, the present study aimed to investigate the rates of respiratory and sleep disturbances in children whose mothers experienced prenatal amniocentesis. 